\title{
Brain Metastases: Epidemiological, Clinical, Diagnosis, Treatment and Outcome Features in Dakar
}

\author{
Alioune Badara Thiam, Maguette Mbaye, Mbaye Thioub, Rel Gerald Boukaka Kala*, \\ El Hadji Cheikh Ndiaye Sy, Mohameth Faye, Kafia Doualeh Ali, Momar Codé Ba, \\ Seydou Boubakar Badiane
}

Neurosurgery Department, Fann Teaching Hospital, Dakar, Senegal

Email: *rel_boukaka@yahoo.fr

How to cite this paper: Thiam, A.B., Mbaye, M., Thioub, M., Kala, R.G.B., Sy, E.H.C.N., Faye, M., Ali, K.D., Ba, M.C. and Badiane, S.B. (2019) Brain Metastases: Epidemiological, Clinical, Diagnosis, Treatment and Outcome Features in Dakar. Open Journal of Modern Neurosurgery, 9 , 410-418.

https://doi.org/10.4236/ojmn.2019.94038

Received: May 27, 2019

Accepted: October 6, 2019

Published: October 9, 2019

Copyright $\odot 2019$ by author(s) and Scientific Research Publishing Inc. This work is licensed under the Creative Commons Attribution International License (CC BY 4.0).

http://creativecommons.org/licenses/by/4.0/

\section{(c) (i) Open Access}

\begin{abstract}
Brain metastases (BM) are the most frequent brain cancer. There are few studies on BM in Senegal. The aim of this study was to describe epidemiological, clinical, diagnosis, treatment and outcome features of patients diagnosed with BM. We conducted a retrospective and descriptive study of patients diagnosed with brain tumors and regularly followed at the neurosurgery department of the "Fann Teaching Hospital (CHNU-Fann)" of Dakar (Senegal) between from January 2010 to December 2017. The medical records of all the patients with evidence histologically diagnosed with BM were reviewed. In our study, 682 medical records of patients with brain tumors were reviewed, and only 20 showed histological evidence of BM (2.9\%). The mean age was 45.45 years. The sex-ratio was 0.43 . Brain CT scan was performed in all the patients (100\%) and brain MRI in 3 patients. The brain lesions were multiple in $70 \%$ of the patients and single in $30 \%$. The histological type of BM was adenocarcinoma (55\%) and squamous cell carcinoma (45\%). Five types of primary cancers were found: lung cancer (50\%), breast cancer (30\%), colorectal cancer (10\%), melanoma (5\%) and one undetermined cancer. All the patients had extirpation surgery; $50 \%$ of the patients died 7 days after the surgery; $25 \%$ had a survival of 3 months after the surgery and $25 \%$ of the patients were lost of sight. Conclusion: The improvement of the screening and diagnosis tests, and the use of the radiation treatment and chemotherapy could allow early management and decrease the death's frequency of the patients with BM in Senegal.
\end{abstract}

\section{Keywords}

Brain Metastases, Surgical Extirpation, Dakar 


\section{Introduction}

The incidence of brain metastases (BM) increased these last years. This could be explained by the improvement of brain imaging and systemic treatments [1] [2]. The management of $\mathrm{BM}$ is multidisciplinary involving neurosurgeons, neuro-anatomopathologists, oncologists and radiotherapists. In our African context, the main difficulties facing the neurosurgeon in Senegal are the inaccessibility of certain diagnostic means and the limitation of the therapeutic methods. These limits have a significant impact on the treatment, prognosis and outcome of the patients. Few studies have been done on BM in sub-Saharan Africa [3]. The aim of this study was to describe epidemiological, clinical, diagnosis, treatment and outcome features of patients diagnosed with brain metastasis at the neurosurgery department of the "Fann Teaching Hospital of Dakar" (Senegal).

\section{Patients and Methods}

We conducted a retrospective and descriptive study of patients diagnosed with brain tumors and regularly followed at the neurosurgery department of the “CHNU-Fann" from January 2010 to December 2017. The medical records of all the patients with evidence histological diagnosed with BM were reviewed. Patients without histology were excluded. The following data were collected: epidemiologic features (age, gender), clinical features (Karnofsky performance scale index, neurological and extra-neurological signs), investigations (computed tomography scan, brain magnetic resonance imaging, abdomino-pelvic Computed tomography scan, mammography, tumors markers), treatment (surgical extirpation, radiation and chemotherapy treatment), outcome (death, survival). The data collected were entered and analyzed with SPSS version 21.0. software. Ethical permission to conduct this work was obtained from Ethical Committee at Fann Teaching Hospital of Dakar.

\section{Results}

In our study, we reviewed 682 medical records of patients with brain tumors, and only 20 showed histological evidence of BM. This makes a frequency of $2.9 \%$. The mean age was 45.45 years. There was a female predominance $(70 \%)$ (Figure 1).

At the admission, 16 patients with BM had unknown primary cancer. Only 4 patients had a known primary cancer with metachronous BM. These were lung cancer (1), breast cancer (1), colorectal cancer (1) and melanoma (1). The Karnofsky performance scale index was greater than or equal to $70 \mathrm{in} 70 \%$ of the patients (Table 1). Clinical signs found were: Intracranial hypertension syndrome (headache, vomiting, visual blur) (90\%), motor deficit (70\%), epilepsy (50\%), cerebellar syndrome (20\%). The consciousness disorders were found in 7 patients (35\%) and 3 of them had a Glasgow score between 12 - 15 and 4 others had a Glasgow score between 8 - 12. Extra neurological signs leading to primary cancer were found in $30 \%$. It was a pulmonary condensation syndrome (15\%), 
breast nodules (10\%) and rectal bleeding (5\%).

Brain CT scan was performed in all the patients (100\%) and a complementary brain MRI in 3 patients. The brain lesions were multiple in $70 \%$ of the patients and single in $30 \%$. These brain lesions predominated in the supra-tentorial stage (70\%) [Figures 2-4]. The assessment was oriented towards primary cancer in $65 \%$ of cases. The histological type of brain metastases was adenocarcinoma (55\%) and squamous cell carcinoma (45\%). Five types of primary cancers were found: lung cancer (50\%), breast cancer (30\%), colorectal cancer (10\%) [Figure 3], one melanoma (5\%) [Figure 5] and one undetermined cancer (5\%) (Table 2).

All the patients had been operated; In this case, it was a surgical extirpation in the presence of a large and deleterious mass effect.

In our study, $50 \%$ of the patients died 7 days after the surgery, $25 \%$ had a survival of 3 months after the surgery and $25 \%$ of the patients were lost of sight (Table 1). None of the surviving patients received additional treatment after surgery.

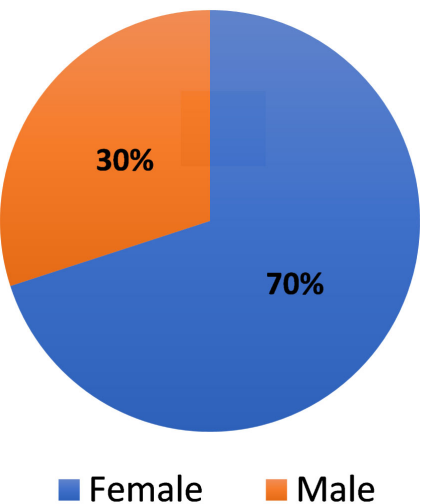

Figure 1. Gender of patients with brain metastases in our study.

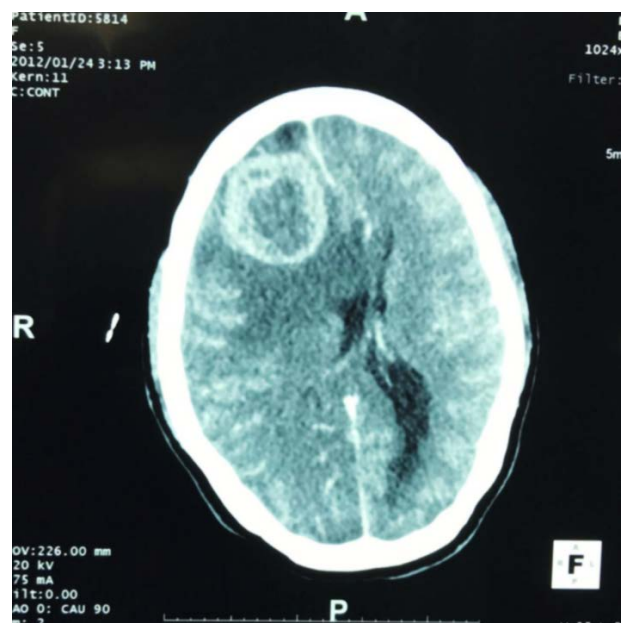

Figure 2. A frontal metachronous brain metastasis with peritumor edema and mass effect of a breast cancer of 37 years old woman; Archive from neurosurgery department of Fann Teaching Hospital. 


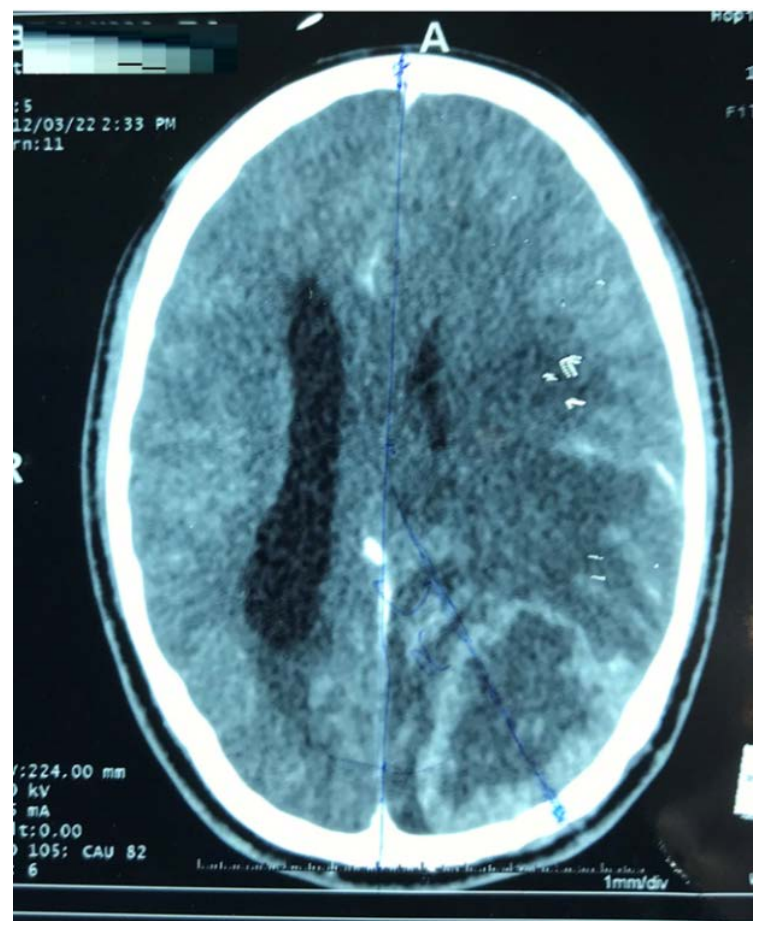

Figure 3. Single brain metastases of a colorectal cancer of 25 years old man in our study. Archive of the neurosurgery department of Fann Teaching Hospital.

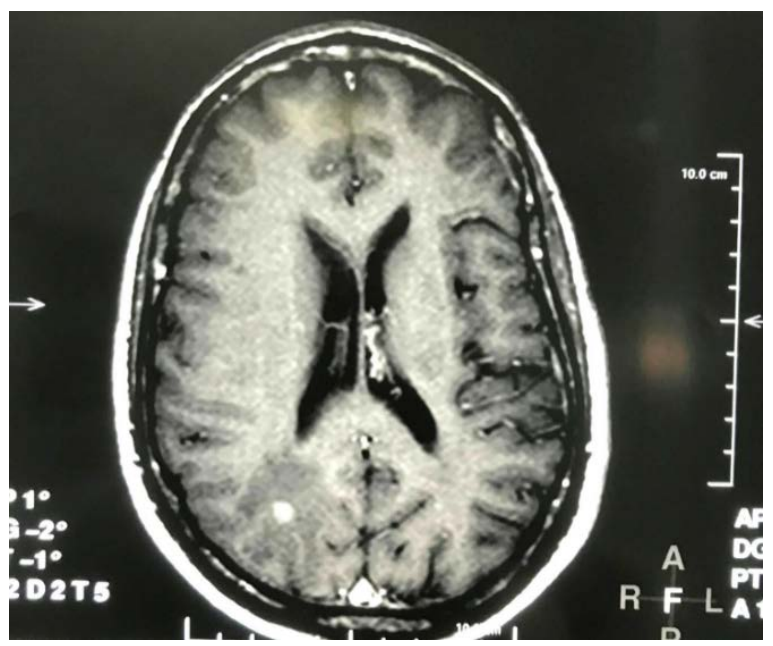

Figure 4. Occipital brain metastasis with peritumor edema of 72 years old patient with melanoma (MRI.T1) archive from neurosurgery department of Fann Teaching Hospital.

Table 1. Different types of primary cancers in patients with brain metastasis in our study.

\begin{tabular}{ccc}
\hline Primary Cancers & Number of Patients & Percentage (\%) \\
\hline Lung cancer & 10 & 50 \\
Breast cancer & 6 & 30 \\
Colorectal cancer & 2 & 10 \\
Melanoma & 1 & 5 \\
Undeterminated & 1 & 5 \\
\hline
\end{tabular}




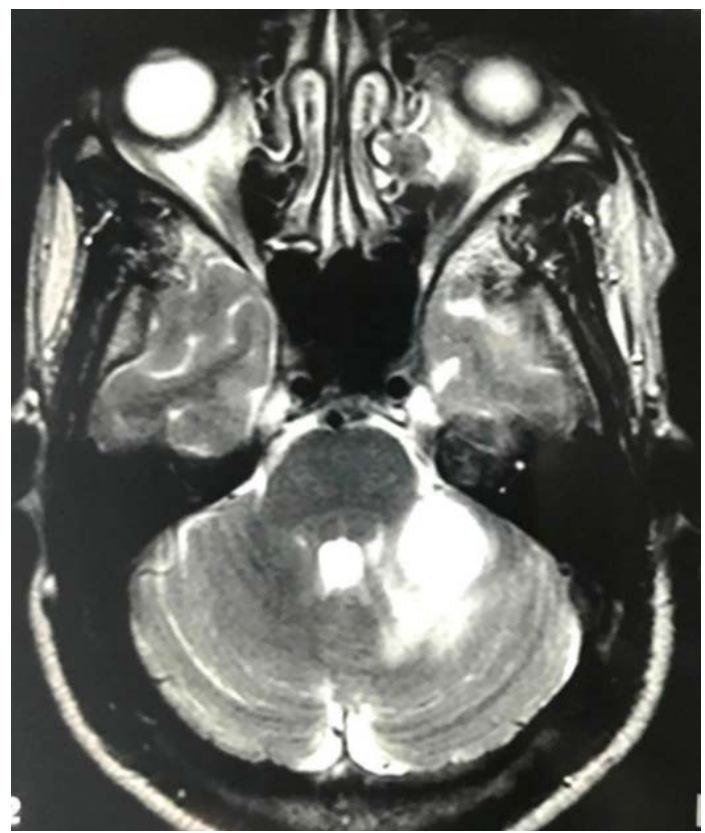

Figure 5. Cerebrellar metastase of the same 72 years old patient with melanoma. Note that this patient had multiple and metachronous brain metastase (MRI. Flair) archive from neurosurgery department of Fann Teaching Hospital.

Table 2. Brain metastases characteristics.

\begin{tabular}{|c|c|c|}
\hline & Number of patients & Percentage (\%) \\
\hline \multicolumn{3}{|l|}{ Onset of brain metastases } \\
\hline Synchronous & 16 & 80 \\
\hline Metachronous & 4 & 20 \\
\hline \multicolumn{3}{|l|}{ Karnofsky index } \\
\hline$\geq 70$ & 14 & 70 \\
\hline 40 & 4 & 20 \\
\hline 10 & 2 & 10 \\
\hline \multicolumn{3}{|l|}{ Brain Imaging } \\
\hline MRI & 3 & 15 \\
\hline CT Scan & 20 & 100 \\
\hline \multicolumn{3}{|l|}{ Histology of brain metastasis } \\
\hline Adenocarcinoma & 11 & 55 \\
\hline Squamous cell carcinoma & 9 & 45 \\
\hline \multicolumn{3}{|l|}{ Treatment } \\
\hline Surgical extirpation & 20 & 100 \\
\hline \multicolumn{3}{|l|}{ Outcome } \\
\hline Death & 10 & 50 \\
\hline Survival of 3 month & 5 & 25 \\
\hline Lost of sight & 5 & 25 \\
\hline
\end{tabular}




\section{Discussion}

The emergence of new imaging methods (CT scan, MRI) and recent advances in oncology, including the appearance of targeted therapies, have improved the management and the survival of patients with cancer. In a context of remission and better control of the systemic disease, the management of BM is becoming a new issue in order to improve the patient's quality of life. The frequency of metastases in our series was $2.9 \%$. In a previous study in Dakar, this frequency was $11.8 \%$ [4] and similar to that found in several African series [3] [5] [6] [7]. In our regions, this result can be explained by the late management of the patients who often die before the diagnosis and by the delay of the anatomopathological tests results. These results are available 3 to 6 months after the surgical extirpation and the patient has already died. Indeed, extemporaneous exam is not performed in our daily practice. The poor archiving of medical patients records and inadequate health coverage of the population can also explain this BM frequency in our series. However, compared to developed countries where BM are currently considered as a public health problem this BM frequency of our study is low [1] [8] [9].

In our series, the female predominance joins the results found by some authors [1] [8] [10]. Other authors reported a male predominance [11], which can be explained by the higher incidence of lung cancer in some countries. Lung cancer is the most common cancer in men [12], while breast cancer the most common in women [8] [13]. The mean age of patients with BM was 47.45 years old. In many countries in Europe, this mean age is about 60 years [1] [10]. This result is linked to the increased life expectancy in these countries.

In $80 \%$ of the patients, BM revealed the disease at the admission namely because our study does not include all the patients who were followed for a primary cancer in oncology and who presented BM subsequently. According to Taillibert et al. [2], in terms of metastatic delay, BM is more frequent in the advanced and poly metastatic stages of the disease. The number of diagnosed single BM has decreased in recent year in benefit to the diagnosed multiple BM because of the improvement in brain imaging (MRI have a better sensitivity than CT scan) and systematic extension investigations.

In our study, extra neurological signs targeting primary cancer found in only $30 \%$ of patients. The poor expression of the primary cancer in metastatic context can be explained by the aggressive nature of this cancer. When BM is the single expression of the primary cancer, some authors [14] associate it with a good prognosis. Only 3 patients performed a brain MRI, which is not ideal because brain MRI is the first-line exam for the diagnosis of BM. Unfortunately, brain MRI remains an expensive exam for the average Senegalese. Imaging showed more patients with single BM (70\%) than multiple BM (30\%) because our neurosurgery department hospitalizes few patients with multiple BM. In our context, a surgical treatment is rarely offered to patients with multiple BM, they are then offered a palliative treatment in other structures. 
The etiological investigations for primary cancer in our patients was limited compared to the standard recommended investigations. It is due to the poor financial status of Senegalese patients as well as our technical platform. The assessment was oriented towards primary cancer in $65 \%$ of the patients and this result returns to the sensitivity of the thoraco-abdominopelvic CT which remains the most available exam for the extension assessment in our context. As in our study adenocarcinoma is the most cancer found in the literature [11]. According to a study of ANOCEF [15], in 54 patients with a known primary cancer and whose CT scan and/or IRM showed BM, a different histology diagnosis was found in 6 of them, which means that although histology is the gold standard diagnosis in cancerology it may have limits.

All the patients were operated but did not received radiation treatment, chemotherapy or targeted therapies, which decrease the success of overall care despite a good surgical treatment. An accessible single BM is optimally treated with surgical extirpation associated with brain radiation treatment, in boot on the lesion focus [16]. Surgical extirpation provides the best results in terms of the local control, quality of life and survival without recurrence [17]. However, recurrence was not to be assessed because of the large number of deaths and the loss of sight. The frequency of death found in our study is consistent with several African series [7]. Nevertheless this frequency remains high compared to data's found in the literature [1] [16]. In our context, this frequency of death can be related to the absence of chemotherapy and radiation treatment in our patients. However, mortality remains related to the uncontrolled outcome of the primary cancer, the appearance of multiple BM [3]. Thus, it not necessary to propose an extirpation surgery to patients whose life expectancy is less than 3 months.

Five patients $(25 \%)$ had a survival of 3 months after the surgery. Studies showed that the median of survival is dependent of the primary cancer [1] [2]. For melanoma's BM, it was ranged from 3 to 6 months before the arrival of targeted therapies, with a 5 -year survival rate of around $3 \%$. Nieder et al. [16] found that a median of survival was improved slightly in their patients from 3.02 to 3.9 months after the treatment. Pratic [7] reports that radiation treatment is the best treatment for postoperative $\mathrm{BM}$, and often the only one treatment for multiple BM. About chemotherapy, its efficacy is difficult to assess because it is rarely used in single treatment (often associated with radiation treatment). Taillibert et al. [18] have shown that $50 \%$ of patients who do not receive brain prophylactic radiation will develop BM, usually within 2 years, whereas these will only be diagnosed in $33.3 \%$ of cases after this radiation, hence the importance of the radiation treatment.

The rate of lost sight is explained by the fact that, culturally, the announcement of the diagnosis of cerebral metastasis is perceived by families as an imminent fatality. Patients with good clinical improvement after surgery no longer find it worthwhile to return to consultation.

The absence of a multidisciplinary consultation meeting and radiation treatment after the diagnosis were factors that limited the enrollment of the patients 
our study. This is due to the fact that during our study, Senegal had only one oncology service, a service that is outside our hospital. Appointments of radiotherapy are very distant, which further reduces the duration of survival.

\section{Conclusion}

The prognosis of the patient with BM is poor when BM is discovered at an advanced stage. Improved screening and diagnostic testing, the use of radiotherapy and other complementary therapies would be excellent support for improving the management of patients with BM. The establishment of a multidisciplinary consultation would be essential.

\section{Conflicts of Interest}

The authors declare no conflicts of interest.

\section{References}

[1] Tabouret, E., Bouchet, L. and Carpentier, F.A. (2013) Epidémiologie des métastases cérébrales et tropisme cérébral. Bulletin du Cancer, 100, 57-62. https://doi.org/10.1684/bdc.2012.1681

[2] Tabouret, E., Chinot, O., Metellus, P., et al. (2012) Recent Trends in Epidemiology of Brain Metastases: An Overview. Anticancer Research, 32, 4655-4662.

[3] Kouassi, K.K.Y., et al. (2018) Profile of Patients with Breast Cancer Brain Metastasis in Abidjan. Advances in Breast Cancer Research, 7, 201-210. https://doi.org/10.4236/abcr.2018.72012

[4] Collomb, H., Dumas, M. and Girard, P.L. (1973) Processus expansifs intracraniens chez le noir au Sénégal. Journal of the Neurological Sciences, 19, 437-452. https://doi.org/10.1016/0022-510X(73)90041-5

[5] Eyenga, V.C., et al. (2008) Etude originale, Les tumeurs du système nerveux central au Cameroun: Histopathologie, démographie. Cahiers Santé, 18, 18-32. https://doi.org/10.1684/san.2008.0096

[6] Konségré, V.A., Lamien-Sanou, A.S., Ouédraogo, W.N., Ramdé, C., Traoré, F., Ido, A., Kabré, O.M. and LompoGoumbri, B.R. (2014) Soudré; Place des méningiomes dans les tumeurs du système nerveux central au centre hospitalier universitaire Yalgado Ouédraogo (CHU-YO) de Ouagadougou: Approche histopathologique. African Journal of Cancer, 6, 235-239. https://doi.org/10.1007/s12558-014-0344-7

[7] Pratic, F. (2012) Profil épidémiologique des métastases cérébrales: Expérience du service de neurochirurgie du CHU de Mohamed VI Marrakech. These Med., Université CADIAYYAD.

[8] Minatani, N., Tanino, H., Kosaka, Y., Kikuchi, M., Nishimiya, H., Waraya, M., Katoh, H., Enomoto, T., Sengoku, N. and Watanabe, M. (2015) Clinicopathological Evaluation and Prognostic Analysis in Breast Cancer Patients with Brain Metastasis. Journal of Cancer Therapy, 6, 727-734. https://doi.org/10.4236/jct.2015.68079

[9] Ducray, F. and Guillevin, R. (2008) Caractéristiques radiologiques des métastases cérébrales. La lettre du Neurologue, 12, 4.

[10] Sperduto, P.W., Kased, N., Roberge, D., et al. (2013) The Effect of Tumor Subtype on the Time from Primary Diagnosis to Development of Brain Metastases and Survival in Patients with Breast Cancer. Journal of Neuro-Oncology, 112, 467-472. 
[11] Park, S., Kim, B., Lee, S. and Kang, G.H. (2007) Panels of Immunohistochemical Markers Help Determine Primary Sites of Metastatic Adenocarcinoma. Archives of Pathology \& Laboratory Medicine, 131, 1561-1567.

[12] Wahba, H., El-Hadaad, H., Anter, A., Ahmad, M. and Ghazy, H. (2018) Outcomes and Prognostic Factors of Small Cell Lung Cancer: A Retrospective Study. Advances in Lung Cancer, 7, 21-31. https://doi.org/10.4236/alc.2018.73003

[13] Gachet et J bull cancer (2011) Métastase cérébrale dans les cancers du sein.

[14] Bartelt, S. and Lutterback, J. (2003) Brain Metastases in Patients with Cancer of Unknown Origin. Journal of Neuro-Oncology, 64, 249-253.

https://doi.org/10.1023/A:1025621819250

[15] ANOCEF (2014) Référentiel ANOCEF Métastases cérébrales.

[16] Nieder, C., Marienhagen, K., Geinitz, H., et al. (2011) Can Current Prognostic Score Reliably Guide Treatment Decisions in Patients with Brain Metastases from Malignant Melanoma? Journal of Cancer Research and Therapeutics, 7, 47-51. https://doi.org/10.4103/0973-1482.80458

[17] Kirsch, D.G., Ledezma, C.J., Mathews, C.S., et al. (2005) Survival after Brain Metastases from Breast Cancer in the Trastuzumab Era. Journal of Clinical Oncology, 23, 2114-2116. https://doi.org/10.1200/JCO.2005.05.249

[18] Taillibert, S. and Le Rhun, E. (2015) Epidémiologie des lésions métastatiques cérébrales. Cancer/ Radiotherapie, 13, 3-9. https://doi.org/10.1016/j.canrad.2014.11.001 